\title{
BMJ Open Cigarette smoking in a Middle Eastern country and its association with hospitalisation use: a nationwide cross-sectional study
}

\author{
Abla Mehio Sibai, ${ }^{1}$ Mohamad Iskandarani, ${ }^{1}$ Andrea Darzi, ${ }^{1}$ Rima Nakkash, ${ }^{1}$ \\ Shadi Saleh, ${ }^{1}$ Souha Fares, ${ }^{1}$ Nahla $\mathrm{Hwalla}^{2}$
}

To cite: Sibai AM, Iskandarani M, Darzi A, et al. Cigarette smoking in a Middle Eastern country and its association with hospitalisation use: a nationwide cross-sectional study. BMJ Open 2016;6: e009881. doi:10.1136/ bmjopen-2015-009881

- Prepublication history for this paper is available online. To view these files please visit the journal online (http://dx.doi.org/10.1136/ bmjopen-2015-009881)

Received 3 September 2015 Revised 7 January 2016 Accepted 1 February 2016

CrossMark

${ }^{1}$ Faculty of Health Sciences, American University of Beirut, Beirut, Lebanon

${ }^{2}$ Faculty of Agriculture and Food Sciences, American University of Beirut, Beirut, Lebanon

Correspondence to Dr Abla Mehio Sibai; am00@aub.edu.lb

\section{ABSTRACT}

Objectives: Little is known about the distribution of cigarette smoking by place and persons at the national level or its burden on healthcare expenditure in countries of the Middle East. We examine in this study the pattern of cigarette smoking by age, gender and geography and assess its association with hospitalisation use in Lebanon, a small middle-income country in the Middle East.

Design: Population-based cross-sectional study.

Setting: The study draws on data collected as part of the nationwide multistage cluster sample Nutrition and Non-Communicable Disease Risk Factor survey conducted in Lebanon in 2009.

Participants: A total of 2836 Lebanese adults 18 years and over.

Measures: Hospitalisation, the outcome variable, was measured using one item and recoded as a dichotomous variable. Cigarette smoking, the main exposure variable, was assessed by examining smoking status and pack-years, capturing intensity, frequency and duration of exposure.

Results: The overall prevalence rate of current smoking in this study was $34.7 \%$, with significantly higher rates in males than females $(42.9 \%$ and $27.5 \%$, respectively). Close to two-thirds of the study population reported ever being hospitalised (62.8\%). Compared to non-smokers, past and current smokers were significantly more likely to be hospitalised, after controlling for sociodemographic and health-related characteristics $(\mathrm{OR}=2.9,95 \% \mathrm{Cl} 1.26$ to 3.34 , and $\mathrm{OR}=1.35,95 \% \mathrm{Cl} 1.12$ to 1.63 , respectively). Hospitalisation use increased significantly in a dose-response manner with increasing pack-years. Conclusions: When compared to regional and international estimates, the prevalence rates of smoking in Lebanon are considerably high, with percentages among women being among the highest in the region. Our findings of increased odds of hospitalisation among ever smokers, net of the effect of comorbidity, underscore the additional burden of smoking on the healthcare bill cost. Continued monitoring of smoking rates and disease surveillance frameworks are warranted in developing countries for policy development and evaluation.

\section{Strengths and limitations of this study}

- The study data are unique, being the first to be collected at the national level in the country, with good external validity.

- Associations between smoking and hospitalisation were evaluated net of the effect of comorbidity and other classical risk factors, suggesting additional pathways for the relationship between smoking and health outcomes.

- The study relied on secondary data analyses; causes of hospitalisation were not available to the authors.

- Reverse causality may pose a potential limitation for some of the observed associations.

\section{INTRODUCTION}

Tobacco smoking has been established as an important risk factor for cardiovascular diseases, cancer, respiratory illnesses and a wide range of other harmful health outcomes. The WHO estimates the mortality rate associated with tobacco smoking at close to six million people per annum with a projected increase to eight million by the year $2030 .{ }^{1}$ Also, smoking accounts for six of eight leading causes of death worldwide and is associated with a large percentage of healthcare costs. ${ }^{2}$

The burden of smoking on healthcare expenditure is notably reflected in the increased rates of hospitalisation as well as longer hospital stays for current and past smokers compared to non-smokers. This has been established in both genders, different age groups and across various settings. ${ }^{3-5}$ Further support for the link between smoking and hospitalisation is evident in studies that examine the impact of public smoking bans on subsequent rates of hospitalisation. For example, Vander Weg et al in a study in the USA showed that risk-adjusted 
hospital admission rates for myocardial infarction and chronic obstructive pulmonary disease had dropped by 20-21\% 3 years after implementation of smoke-free legislations. Similar results have been established in studies assessing tobacco control policies and public smoking bans in Switzerland. ${ }^{7}$ Recent data indicate that about $70 \%$ of current smokers' excess medical care costs are preventable by quitting. ${ }^{8}$

Research addressing the prevalence of smoking and its related health risks has received increasing attention over the past years across the globe and more recently in the developing world. Eighty per cent of the world's one billion smokers reside in low and middle-income countries. These countries carry the higher burden of smoking-related mortality, morbidity and healthcare cost. Among its neighbouring Arab countries, Lebanon, a middle-income country of the Mediterranean region (around 4 million population and a GDP of US\$9284 per capita), has been witnessing alarming rates of smoking among men and women. For example, close to $33 \%$ of adults aged 18 years and over in Beirut, the capital city, report current cigarette use, with a higher percentage among men than women $(44 \%$ and $23 \%$, respectively). ${ }^{9}$ Cigarette smoking is also prevalent in significant proportions among physicians $(30.7 \%)$, pregnant women $(20 \%)$ and university students (19.2\%), with recent data indicating that younger women are increasingly adopting smoking behaviour that parallels those of men. ${ }^{10-12}$ Yet these studies are limited by being small scaled, focusing on only one segment of the population. Also, evidence linking tobacco consumption with healthcare utilisation remains largely lacking in Lebanon and the Mediterranean region. Drawing on recent data collected at the national level, this study examines the prevalence of cigarette smoking in Lebanon, its pattern of use by age, gender and locality (governorates), and assesses the association of cigarette smoking and other sociodemographic and health-related characteristics with hospital use. The paper provides detailed information on differentials in hospitalisation use between smokers and non-smokers and among various intensities of life-time cigarette consumption levels. It aims to better inform decision-makers and public health campaigns of the impact of cigarette smoking on medical expenditure, focusing on hospital use. The findings also serve as a benchmark for future assessments of the burden of smoking in the country and evaluations of policy interventions.

\section{METHODS}

\section{Study design and sampling}

This study relied on secondary analyses of data drawn from the Nutrition and Non-communicable Disease Risk Factor (NNCD-RF) survey. The NNCD-RF survey was a population-based cross-sectional study conducted on a nationally representative Lebanese sample between the years 2008 and 2009. A stratified, multistage cluster household sampling design was used with Lebanese Governorates constituting the strata from which clusters at the district level, both urban and rural, were selected. The primary sampling units were households, with one adult aged 18 years and over randomly selected from within each household to participate in the survey, using the Kish method. ${ }^{13}$ Refusals did not exceed $10.7 \%$, yielding a final sample of 2836 participants (1332 males and 1504 females). Further details of the study conduct and methods are presented elsewhere. ${ }^{14}$

\section{Measures}

The study followed the WHO STEPwise approach and guidelines in the data collection process and interview schedule for surveillance of NCD risk factors. ${ }^{15}$ In the first step, participants responded to a comprehensive questionnaire using face-to-face interviews by welltrained research assistants with a public health or nutrition background. The questionnaire targeted information on demographic and socioeconomic characteristics, smoking and alcohol consumption, health conditions and comorbidity, and healthcare seeking behaviour. ${ }^{16}$ Smoking is referred to hereafter in this paper to indicate 'cigarette smoking'. In the second step, anthropometric and blood pressure measurements were obtained using standardised methods and calibrated equipment. The Institutional Review Board of the American University of Beirut approved the original study design and conduct, and informed consent was obtained from all participants.

Information on cigarette smoking, the main exposure variable, was elicited in terms of status (never, past and current), duration (age at initiation and age at stopping for past smokers), frequency (number of days of smoking per week) and intensity (average number of packs consumed per day). Consequently, 'pack-years' was estimated for ever smokers by multiplying the average number of packs smoked per day by the number of years of exposure. This yielded a continuous score ranging from 0 (for never smokers) to a maximum of 184 pack-years (for ever smokers). The measure pack-years, capturing life-time cigarettes smoking exposure, was then grouped into four categories (0, 1-19, 20-39, 40-59 and $\geq 60$ pack-years).

The main outcome variable, hospitalisation, was measured using one item 'Have you ever been hospitalized for at least one night, other than those for delivery?' and was recoded as a dichotomous variable (yes/no). The study also examined several covariates which were assessed alongside two broad categories, namely sociodemographic and health-related variables. Sociodemographic information included age (grouped into four categories: $18-34,35-49,50-64, \geq 65$ years), gender, marital status (single, married, divorced/ widowed), governorate (Beirut, Mount Lebanon, North, South, Bekaa), educational level (elementary or less, secondary or technical, and university), working status (yes, no), insurance coverage and type (none, private, and 
public including the National Social Security Fund (NSSF) and the Civil Servant Cooperative (COOP) and military). The NSSF covers employees in the private sector, while the COOP/military covers the civil servants in the public and governmental sector. Health-related characteristics included self-rated health (excellent, good, weak), behaviours (physical activity using the short version of the International Physical Activity Questionnaire $^{17}$ and alcohol intake coded as a 4category variable: none or occasional, $<1-2$ times/week, 3-6 times/week, and daily), body mass index (BMI) and self-reported medical conditions (hypertension, hyperlipidaemia, diabetes and heart disease, and other comorbid conditions, all considered as dichotomous variables).

\section{Statistical analysis}

Prevalence estimates, expressed as numbers, percentages and means, for smoking status and intensity were calculated for the total study population and stratified by age, gender and governorate. Similarly, frequencies and descriptive statistics were estimated for sociodemographic, behavioural and health-related factors for the total sample population, as well as by hospitalisation status. Associations between the various covariates and hospital use were measured using prevalence ORs (POR) and their 95\% CIs, adjusted for age. The percentage of missing data was minimal, with less than $4 \%$ of the data being missing for any single variable. Cases with missing information were excluded from the analyses. Logistic regression analyses were then conducted to estimate the prevalence odds of hospitalisation, first by smoking status and second by pack-years, adjusted for all potential confounders (age, gender, governorate, education, working status, insurance type, self-rated health, hypertension, hyperlipidaemia, diabetes heart disease and other comorbid conditions). In this analysis, and with smoking being the main exposure, the study sample was considered to be adequately powered to detect an OR of 2.0 in a logistic regression analysis that adjusts for all the covariates included in the model. ${ }^{18}$ All statistical analyses were performed using the Statistical Software Package for Social Sciences (SPSS V.20), and a $p$ value $<0.05$ was considered significant.

\section{RESULTS}

Table 1 shows the distribution of smoking status and lifetime smoking consumption (pack-year) by age and gender. One-third of the study participants were current smokers $(34.7 \%)$, with higher rates in males than in females $(42.9 \%$ and $27.5 \%$, respectively). Prevalence rates of current smoking increased with increasing age, reaching its maximum value in the age group 35-49 in males $(52.1 \%)$, and in the older age group 50-64 in females $(45.1 \%)$, declining thereafter. A higher proportion of males than females were quitters $(15.8 \%$ and $11.9 \%$ among ever smokers, respectively); this disparity was most noted in the 50-64 age group. Among eversmokers, mean pack-year was significantly higher for males than for females $(36.9 \pm 1.6$ and $22.9 \pm 1.0$, respectively; $p$ value $<0.05$ ) and increased consistently with increasing age, notably among males.

The distributions of the sociodemographic and health characteristics are shown in tables 2 and 3, respectively,

Table 1 Per cent distribution of smoking (status and pack-years) by age and gender among Lebanese adults, 2009

\begin{tabular}{|c|c|c|c|c|c|c|c|c|c|c|}
\hline \multirow[b]{2}{*}{ Total } & \multicolumn{4}{|c|}{ Smoking status } & \multicolumn{6}{|c|}{ Pack-years } \\
\hline & $\begin{array}{l}\text { Never } \\
(\%) \\
59.5\end{array}$ & $\begin{array}{l}\text { Past } \\
(\%) \\
5.8\end{array}$ & $\begin{array}{l}\text { Current } \\
(\%) \\
34.7\end{array}$ & $\begin{array}{l}\text { Quitters* (\%) } \\
14.3\end{array}$ & $\begin{array}{l}0(\%) \\
59.8\end{array}$ & $\begin{array}{l}1-19(\%) \\
19.2\end{array}$ & $\begin{array}{l}20-39(\%) \\
9.4\end{array}$ & $\begin{array}{l}40-59(\%) \\
6.2\end{array}$ & $\begin{array}{l}\geq 60(\%) \\
5.3\end{array}$ & $\begin{array}{l}\text { Mean } \pm S E * \\
31.2 \pm 1.1\end{array}$ \\
\hline Males & 49.0 & 8.1 & 42.9 & 15.9 & 49.1 & 21.5 & 11.8 & 8.3 & 9.2 & $36.9 \pm 1.6$ \\
\hline \multicolumn{11}{|c|}{ Age (years) } \\
\hline 18-34 & 60.4 & 2.2 & 37.4 & 5.5 & 60.7 & 31.8 & 5.8 & 1.3 & 0.3 & $13.6 \pm 2.0$ \\
\hline $35-49$ & 41.0 & 6.9 & 52.1 & 11.7 & 41.1 & 18.1 & 21.8 & 10.6 & 8.3 & $34.6 \pm 1.8$ \\
\hline $50-64$ & 39.4 & 12.8 & 47.8 & 21.1 & 39.7 & 6.7 & 12.5 & 17.9 & 23.2 & $58.8 \pm 3.2$ \\
\hline$\geq 65$ & 36.6 & 27.5 & 35.9 & 43.4 & 36.6 & 10.5 & 11.1 & 16.3 & 25.5 & $68.0 \pm 5.8$ \\
\hline Females & 68.8 & 3.7 & 27.5 & 11.9 & 69.0 & 17.3 & 8.1 & 3.7 & 1.9 & $22.9 \pm 1.0$ \\
\hline \multicolumn{11}{|c|}{ Age (years) } \\
\hline 18-34 & 84.8 & 0.9 & 14.3 & 5.9 & 85.1 & 14.2 & 0.6 & 0.0 & 0.2 & $7.8 \pm 1.7$ \\
\hline $35-49$ & 60.0 & 3.4 & 36.6 & 8.5 & 60.1 & 21.2 & 14.2 & 3.4 & 1.1 & $20.6 \pm 1.1$ \\
\hline $50-64$ & 48.5 & 6.4 & 45.1 & 12.4 & 48.5 & 19.2 & 14.0 & 12.3 & 6 & $33.3 \pm 2.3$ \\
\hline$\geq 65$ & 57.0 & 13.4 & 29.6 & 31.2 & 57.4 & 16.3 & 12.8 & 7.1 & 6.4 & $33.8 \pm 3.7$ \\
\hline \multicolumn{11}{|c|}{ Governorate } \\
\hline Beirut & 59.2 & 5.5 & 35.3 & 13.5 & 59.2 & 19.4 & 12.0 & 5.2 & 4.2 & $29.1 \pm 2.5$ \\
\hline Mount & 59.1 & 6.5 & 34.4 & 15.9 & 59.5 & 19.7 & 8.8 & 6.2 & 5.9 & $32.9 \pm 1.8$ \\
\hline North & 59.6 & 6.4 & 34.0 & 15.8 & 60.2 & 20.2 & 9.6 & 5.8 & 4.2 & $27.4 \pm 1.9$ \\
\hline South & 59.2 & 2.8 & 38.0 & 6.9 & 59.7 & 17.8 & 11.2 & 5.8 & 5.6 & $32.4 \pm 2.7$ \\
\hline Bekaa & 61.0 & 6.6 & 32.4 & 16.9 & 61.0 & 18.2 & 9.8 & 5.2 & 5.8 & $30.6 \pm 2.8$ \\
\hline
\end{tabular}


Table 2 Distribution of the sociodemographic characteristics in the total sample and their association with hospitalisation rate, 2009

\begin{tabular}{|c|c|c|c|c|c|c|c|c|}
\hline \multirow[b]{3}{*}{ Total } & \multicolumn{2}{|c|}{ Total sample } & \multicolumn{4}{|c|}{ Hospitalisation } & \multicolumn{2}{|c|}{ Age-adjusted } \\
\hline & \multirow[b]{2}{*}{$\mathbf{N}$} & \multirow[b]{2}{*}{ Per cent } & \multicolumn{2}{|l|}{ No } & \multicolumn{2}{|l|}{ Yes } & \multirow[b]{2}{*}{ POR } & \multirow[b]{2}{*}{$95 \% \mathrm{Cl}$} \\
\hline & & & $\begin{array}{l}n \\
1053\end{array}$ & $\begin{array}{l}\text { Per cent } \\
37.2\end{array}$ & $\begin{array}{l}n \\
1781\end{array}$ & $\begin{array}{l}\text { Per cent } \\
62.8\end{array}$ & & \\
\hline \multicolumn{9}{|l|}{ Age } \\
\hline $18-34$ & 1264 & 44.6 & 624 & 49.4 & 639 & 50.6 & 1.00 & \\
\hline $35-49$ & 816 & 28.8 & 301 & 36.9 & 515 & 63.1 & 1.67 & 1.39 to 2.00 \\
\hline $50-64$ & 461 & 16.3 & 101 & 22.0 & 359 & 78.0 & 3.47 & 2.77 to 4.44 \\
\hline$\geq 65$ & 295 & 10.3 & 27 & 9.2 & 268 & 90.8 & 9.69 & 6.43 to 14.01 \\
\hline \multicolumn{9}{|l|}{ Gender } \\
\hline Female & 1504 & 53.0 & 618 & 41.1 & 884 & 58.9 & 1.00 & \\
\hline Male & 1332 & 47.0 & 435 & 32.7 & 897 & 67.3 & 1.45 & 1.23 to 1.70 \\
\hline \multicolumn{9}{|l|}{ Marital status } \\
\hline Single & 995 & 35.1 & 475 & 47.8 & 519 & 52.2 & 1.00 & \\
\hline Married & 1621 & 57.2 & 537 & 33.1 & 1083 & 66.9 & 1.15 & 0.94 to 1.40 \\
\hline Divorced/widowed & 218 & 7.7 & 39 & 17.9 & 179 & 82.1 & 1.33 & 0.87 to 2.03 \\
\hline \multicolumn{9}{|l|}{ Governorate } \\
\hline Beirut & 309 & 10.9 & 137 & 44.3 & 172 & 55.7 & 1.00 & \\
\hline Mount & 1213 & 42.8 & 453 & 37.3 & 760 & 62.7 & 1.19 & 0.91 to 1.55 \\
\hline North & 500 & 17.6 & 194 & 39.0 & 304 & 61.0 & 1.30 & 0.96 to 1.75 \\
\hline South & 466 & 16.4 & 150 & 32.2 & 316 & 67.8 & 1.60 & 1.17 to 2.17 \\
\hline Bekaa & 346 & 12.2 & 119 & 34.4 & 227 & 65.6 & 1.40 & 1.01 to 1.95 \\
\hline \multicolumn{9}{|l|}{ Education } \\
\hline Elementary or less & 1260 & 44.4 & 372 & 29.5 & 887 & 70.5 & 1.00 & \\
\hline Secondary or technical & 736 & 26.0 & 297 & 40.4 & 438 & 59.6 & 0.87 & 0.71 to 1.07 \\
\hline University & 840 & 29.6 & 384 & 45.7 & 456 & 54.3 & 0.80 & 0.66 to 0.98 \\
\hline \multicolumn{9}{|l|}{ Working status } \\
\hline No & 1457 & 51.4 & 531 & 36.5 & 924 & 63.5 & 1.00 & \\
\hline Yes & 1378 & 48.6 & 521 & 37.8 & 857 & 62.2 & 1.18 & 1.01 to 1.39 \\
\hline \multicolumn{9}{|l|}{ Insurance type } \\
\hline None & 1139 & 40.2 & 458 & 40.3 & 619 & 59.7 & 1.00 & \\
\hline Private & 499 & 17.6 & 200 & 40.1 & 299 & 59.9 & 1.09 & 0.87 to 1.37 \\
\hline Public NSSF & 804 & 28.3 & 286 & 35.6 & 518 & 64.4 & 1.26 & 1.04 to 1.54 \\
\hline Governmental COOP/Military & 394 & 13.9 & 109 & 27.7 & 285 & 72.3 & 1.59 & 1.23 to 2.07 \\
\hline
\end{tabular}

in the total sample and stratified by hospitalisation status. The sample consisted in the majority of younger adults $(44.6 \%)$ in the age $18-34$ years, with a slightly larger percentage of females $(53 \%)$ than males $(47.0 \%)$. Ever been hospitalised increased significantly with increasing age, and was higher in males than in females (age adjusted POR $=1.45,95 \%$ CI 1.23 to 1.70 ) (table 2). Also, hospitalisation declined with increasing levels of education, and was significantly higher in the South and Bekaa in comparison to other governorates. Participants covered by public and governmental insurance schemes (NSSF and the COOP/Military) were also significantly more likely to be hospitalised than those covered by the private insurance or the uninsured ( $p$ value $<0.001$ ).

The proportion of ever smokers in the total sample approached $40 \%$ with close to half of these (19.3\%) having accumulated over a lifetime between 1 and 19 pack-years (table 3 ). The majority perceived their health status as good $(58.7 \%)$ and excellent $(33.2 \%)$. Close to half of the sample was involved in moderate or high physical activity levels (31.9\% and 21.8\%, respectively). Only $2.6 \%$ reported daily alcohol consumption. Obesity was identified in one of four study participants. Hypertension was the most prevalent comorbid condition $(27.2 \%)$, followed by hyperlipidaemia $(15.2 \%)$, diabetes $(7.1 \%)$ and heart disease $(6.3 \%)$. Compared to the never smokers $(56.9 \%)$, the odds of hospitalisation were noted to be highest among past smokers (POR: 2.68, $95 \%$ CI 1.66 to 9.33 ) followed by current smokers (POR: 1.46, 95\% CI 1.22 to 1.74) (table 3). Hospitalisation increased consistently with increasing pack-years in a dose-response fashion, yielding a rate of $86 \%$ among smokers of $\geq 60$ pack-years. Also, hospitalisation use was significantly higher among those perceiving their health as weak, and those reporting hyperlipidaemia, diabetes, heart disease and other comorbid conditions compared to their counterparts.

Table 4 presents the results of the multivariate logistic regression with smoking status and pack-years as the main exposure variables, and hospitalisation as the 
Table 3 Distribution of the health-related characteristics in the total sample and their association with hospitalisation rate, 2009

\begin{tabular}{|c|c|c|c|c|c|c|c|c|}
\hline & \multirow{2}{*}{\multicolumn{2}{|c|}{ Total sample }} & \multicolumn{4}{|c|}{ Hospitalisation } & \multirow{2}{*}{\multicolumn{2}{|c|}{ Age-adjusted }} \\
\hline & & & \multicolumn{2}{|c|}{ No } & \multicolumn{2}{|l|}{ Yes } & & \\
\hline & $\mathbf{N}$ & Per cent & $\mathrm{n}$ & Per cent & $\mathrm{n}$ & Per cent & $\overline{\text { POR }}$ & $95 \% \mathrm{Cl}$ \\
\hline \multicolumn{9}{|c|}{ Cigarette smoking status } \\
\hline Never & 1686 & 59.5 & 726 & 43.1 & 959 & 56.9 & 1.00 & \\
\hline Ex-smoker & 164 & 5.8 & 22 & 13.4 & 142 & 86.6 & 2.68 & 1.66 to 4.33 \\
\hline Current & 984 & 34.7 & 303 & 30.8 & 680 & 69.2 & 1.46 & 1.22 to 1.74 \\
\hline \multicolumn{9}{|l|}{ Pack-year } \\
\hline 0 & 1686 & 59.7 & 726 & 43.0 & 959 & 57.0 & 1.00 & \\
\hline $1-19$ & 545 & 19.3 & 190 & 34.9 & 355 & 65.1 & 1.44 & 1.18 to 1.77 \\
\hline $20-39$ & 267 & 9.5 & 79 & 29.6 & 188 & 70.4 & 1.34 & 1.00 to 1.79 \\
\hline $40-59$ & 175 & 6.2 & 33 & 18.9 & 142 & 81.1 & 2.06 & 1.34 to 3.18 \\
\hline$>60$ & 151 & 5.3 & 21 & 14.0 & 129 & 86.0 & 2.25 & 1.37 to 3.70 \\
\hline \multicolumn{9}{|l|}{ Self-rated health } \\
\hline Excellent & 937 & 33.2 & 440 & 47.0 & 497 & 53.0 & 1.00 & \\
\hline Good & 1659 & 58.7 & 571 & 34.4 & 1087 & 65.6 & 1.43 & 1.02 to 1.70 \\
\hline Weak & 230 & 8.1 & 40 & 17.4 & 190 & 82.6 & 3.00 & 2.07 to 4.40 \\
\hline \multicolumn{9}{|l|}{ Physical activity } \\
\hline Low & 1319 & 46.5 & 479 & 36.3 & 840 & 63.7 & 1.00 & \\
\hline Moderate & 882 & 31.1 & 320 & 36.3 & 562 & 63.7 & 0.89 & 0.75 to 1.08 \\
\hline High & 618 & 21.8 & 246 & 39.9 & 370 & 60.1 & 0.85 & 0.69 to 1.04 \\
\hline \multicolumn{9}{|l|}{ Alcohol in past year } \\
\hline None/occasional & 2241 & 79.0 & 847 & 37.8 & 1392 & 62.2 & 1.00 & \\
\hline$<1-2$ times/week & 437 & 15.4 & 162 & 37.1 & 275 & 62.9 & 1.06 & 0.85 to 1.32 \\
\hline 3-6 times/week & 83 & 2.9 & 26 & 31.3 & 57 & 68.7 & 1.44 & 0.89 to 2.35 \\
\hline$\geq 7$ times/week & 75 & 2.6 & 18 & 24.0 & 57 & 76.0 & 1.61 & 0.92 to 2.82 \\
\hline \multicolumn{9}{|l|}{ BMI } \\
\hline Normal & 1104 & 39.5 & 475 & 43.1 & 628 & 56.9 & 1.00 & \\
\hline Overweight & 987 & 35.3 & 348 & 35.3 & 639 & 64.7 & 1.06 & 0.88 to 1.28 \\
\hline Obese & 704 & 25.2 & 218 & 31.0 & 486 & 69.0 & 1.04 & 0.84 to 1.30 \\
\hline \multicolumn{9}{|l|}{ Hypertension } \\
\hline No & 2038 & 72.8 & 854 & 41.9 & 1183 & 58.1 & 1.00 & \\
\hline Yes & 763 & 27.2 & 186 & 24.4 & 577 & 75.6 & 1.20 & 0.97 to 1.49 \\
\hline \multicolumn{9}{|l|}{ Hyperlipidaemia } \\
\hline No & 2406 & 84.8 & 974 & 40.5 & 1430 & 59.5 & 1.00 & \\
\hline Yes & 430 & 15.2 & 79 & 18.4 & 351 & 81.6 & 1.87 & 1.42 to 2.46 \\
\hline \multicolumn{9}{|l|}{ Diabetes } \\
\hline No & 2540 & 92.9 & 1026 & 38.9 & 1614 & 61.1 & 1.00 & \\
\hline Yes & 194 & 7.1 & 27 & 13.9 & 167 & 86.1 & 1.87 & 1.20 to 2.89 \\
\hline \multicolumn{9}{|l|}{ Heart disease } \\
\hline No & 2657 & 93.7 & 1047 & 39.4 & 1609 & 60.6 & 1.00 & \\
\hline Yes & 178 & 6.3 & 6.0 & 3.4 & 172 & 96.6 & 8.12 & 3.53 to 18.67 \\
\hline \multicolumn{9}{|c|}{ Other comorbid conditions } \\
\hline No & 1999 & 70.7 & 871 & 43.6 & 1127 & 56.4 & 1.00 & \\
\hline Yes & 830 & 29.3 & 180 & 21.7 & 650 & 78.3 & 2.05 & 1.69 to 2.50 \\
\hline
\end{tabular}

outcome. In the fully adjusted model, ever smokers were significantly at higher odds of hospitalisation than nonsmokers, with the magnitude of the association being larger for the past smokers than the current smokers $(\mathrm{OR}=2.09,95 \%$ CI 1.26 to 3.44 ; and $\mathrm{OR}=1.35,95 \%$ CI 1.12 to 1.63 , respectively). Hospitalisation rates increased with increasing life-time exposure to smoking ( $\mathrm{p}$ for trend $<0.01)$. Life-time consumption of 40-59 pack-years and $\geq 60$ pack years showed significant associations with hospitalisation use with an adjusted POR $=1.68$ (95\% CI 1.06 to 2.67$)$ and $\mathrm{POR}=2.01(95 \%$ CI 1.15 to 3.49$)$, respectively. When compared to the non-insured, the $\mathrm{COOP} /$ military public insurance schemes had higher odds of hospitalisation than their counterparts ( $\mathrm{POR}=1.80)$, for both regression models of smoking status and pack-years.

\section{DISCUSSION}

This study adds to the growing body of knowledge in the developing world showing evidence of the hazards of tobacco use, with a focus on the association of cigarette 
Table 4 Multivariate analysis: smoking and hospitalisation use

\begin{tabular}{|c|c|c|c|c|}
\hline & \multicolumn{2}{|c|}{$\begin{array}{l}\text { Model with smoking status as main } \\
\text { exposure }\end{array}$} & \multicolumn{2}{|c|}{$\begin{array}{l}\text { Model with pack-years as main } \\
\text { exposure }\end{array}$} \\
\hline & Fully-adjusted POR & $95 \% \mathrm{Cl}$ & Fully-adjusted POR & $95 \% \mathrm{Cl}$ \\
\hline \multicolumn{5}{|l|}{ Exposure variable } \\
\hline Smoking status (never) & 1.00 & & & \\
\hline Ex-smoker & 2.09 & 1.26 to 3.44 & & \\
\hline Current & 1.35 & 1.12 to 1.63 & & \\
\hline Pack -year (0) & & & 1.00 & \\
\hline $1-19$ & & & 1.38 & 1.11 to 1.71 \\
\hline $20-39$ & & & 1.17 & 0.86 to 1.59 \\
\hline $40-59$ & & & 1.68 & 1.06 to 2.67 \\
\hline$\geq 60$ & & & 2.01 & 1.15 to 3.49 \\
\hline $\mathrm{p}$ Value for trend & & & $<0.01$ & \\
\hline \multicolumn{5}{|l|}{ Sociodemographic characteristics } \\
\hline Gender (female) & 1.00 & & & \\
\hline Male & 1.61 & 1.32 to 2.00 & 1.60 & 1.32 to 1.96 \\
\hline Age (18-34) & 1.00 & & 1.00 & \\
\hline $35-49$ & 1.25 & 1.02 to 1.53 & 1.26 & 1.03 to 1.55 \\
\hline $50-64$ & 1.97 & 1.47 to 2.66 & 1.91 & 1.41 to 2.60 \\
\hline$\geq 65$ & 4.40 & 2.71 to 7.15 & 4.46 & 2.74 to 7.26 \\
\hline Governorate (Beirut) & 1.00 & & 1.00 & \\
\hline Mount & 1.24 & 0.94 to 1.64 & 1.24 & 0.94 to 1.63 \\
\hline North & 1.31 & 0.95 to 1.81 & 1.32 & 0.96 to 1.82 \\
\hline South & 1.67 & 1.20 to 2.32 & 1.65 & 1.19 to 2.30 \\
\hline Bekaa & 1.44 & 1.01 to 2.06 & 1.44 & 1.01 to 2.04 \\
\hline Education (elementary or below) & 1.00 & & 1.00 & \\
\hline Secondary or technical & 0.93 & 0.75 to 1.16 & 0.95 & 0.76 to 1.17 \\
\hline University & 0.85 & 0.68 to 1.07 & 0.86 & 0.68 to 1.08 \\
\hline Working status (not working) & 1.00 & & & \\
\hline Working & 1.11 & 0.91 to 1.34 & 1.10 & 0.91 to 1.34 \\
\hline Insurance type (none) & 1.00 & & & \\
\hline Private insurance & 1.37 & 1.06 to 1.78 & 1.40 & 1.08 to 1.81 \\
\hline Public NSSF & 1.44 & 1.16 to 1.79 & 1.45 & 1.17 to 1.80 \\
\hline Governmental COOP/military & 1.80 & 1.36 to 2.37 & 1.80 & 1.37 to 2.38 \\
\hline
\end{tabular}

smoking with hospitalisation use. Ever smokers, current and past smokers, were significantly more likely to have been hospitalised in comparison to those who had never smoked, net of the effect of established cardiovascular risk factors and comorbidity. The intensity and duration of smoking, measured in terms of life-time consumption of pack-years, showed a significant dose-response relationship with hospital use.

Current prevalence rates of smoking in Lebanon from this study are estimated at $35 \%$. This figure is among the highest in the region and exceeds estimates obtained from the USA $(23 \%)$ and Europe (26\% in Great Britain, $27 \%$ in Germany and $30 \%$ in France). ${ }^{2}$ In the Arab region, smoking prevalence rates vary, ranging from as low as $20 \%$ in Bahrain and Egypt to high rates in Tunisia $(31 \%)$ and Kuwait (34.4\%). ${ }^{1}{ }^{19}$ Also, national estimates for ex-smoking rates from this study $(5.8 \%)$ appear to be one of the lowest compared to countries worldwide and in the region. For example, ex-smoking rates approach $32 \%$ in the USA and $10.2 \%$ in Saudi Arabia. ${ }^{20} 21$
As elsewhere, men in Lebanon were more likely to be smokers than women (1.6 times). Historically, men exhibited much greater prevalence rates than women, with the ratio reaching as high as 5-1 in certain regions. ${ }^{22}$ While the lower smoking rates in women are likely to be attributed to under-reporting and social desirability biases, this gender differential has been declining worldwide, as women are increasingly adopting smoking behaviour that parallels those of men, to the extent that sex ratios are approaching 1 in France and reaching below 1 in Norway. ${ }^{23}$ In Lebanon, the gap in smoking between men and women has been relatively narrow as early as the 1960s (male to female ratio not exceeding two), ${ }^{24}$ and appears to be among the lowest when compared to estimates from neighbouring countries. For example, the male-to-female smoking ratio is 5.33 in Syria, 9.53 in Jordan and 27 in Saudi Arabia. $^{21} 2526$ Lebanon has long been characterised as more liberal than other Arab societies, with westernisation and diminishing cultural constraints on women's 
behaviour contributing to the consistently high prevalence rates among women in the country. In contrast, sociocultural traditions in most countries of the Arab region, including male dominance and the limited opportunity for the majority of women for work and risk exposures, may have influenced the overall low female smoking rates. ${ }^{23}$

Our study showed a direct and significant relationship between smoking and hospitalisation. Past and current smokers were significantly more likely to have been hospitalised than those who had never smoked, net of the effect of comorbidity. Similarly, percentages of hospitalisation use increased significantly with increasing packyears. The higher odds of hospitalisation in past smokers in comparison to current smokers corroborate findings from other studies elsewhere. ${ }^{5} 2728$ This is likely to be due to reverse causality, with smokers who have developed a serious chronic illness resulting in hospitalisation being more likely to quit smoking. Indeed, post hoc analysis of our data revealed that $65 \%$ of past smokers reported deteriorating health as the main reason for quitting smoking. Hence, declining health and incident diseases requiring hospitalisation become the cause for quitting rather than the consequence, a phenomenon described as the 'ill quitter' effect. ${ }^{29}$

The observed differentials in the proportions of hospitalisation by the various insurance coverage schemes in our study merit some consideration. Our analyses revealed that those covered by governmental and military schemes were particularly at higher odds of hospitalisation than their counterpart, net of the effect of sociodemographic characteristics and comorbidity. A number of explanations are offered here. First, this may partly be due to the self-selection of the 'older and sicker' population into such public insurance modalities, ${ }^{30}$ thus potentiating a greater use of hospital services. Alternatively, it may be attributed to the specific nature of services offered across the different insurance schemes in Lebanon. In comparison to the private sector and the NSSF, the schemes covering the civil servants (both COOP and military) present themselves with a less rigid gatekeeping rein and less complex bureaucratic admission processes, which may increase the likelihood of health-seeking behaviour and act as push factors towards enhanced utilisation of hospital care.

The findings of this study need to be considered in the light of the following limitations. Given the inherent limitation of cross-sectional study designs, one can only draw an association but not solid causal inferences from our study. As mentioned earlier, reverse causality is a likely explanation for the relatively large magnitude of the association between past smoking and hospitalisation. Also, the outcome 'ever been hospitalized' is a crude measure and does not detail the reasons for hospitalisation, or whether admissions were due to smoking-related diseases. Yet, with smoking being a lifetime exposure and hospital use being a recurrent event, the relationship between smoking and hospital use is better captured using hospital use over time, rather than within a certain limited recall period. Additionally, including hospitalisations which are not necessarily due to smoking-related diseases is likely to have attenuated associations, with the current findings being considered underestimates of the magnitude of the association between cigarette smoking and hospital use. Furthermore, the observed regression estimates of smoking effect may have been affected by residual or unmeasured confounding bias, owing to the use of crude measures of certain variables that have been only partially controlled for (eg, the use of dichotomous measures of comorbidity) or the omission of others from the regression model (eg, marital status or indicators of income). Finally, early life exposure to high intensity smoking doses may have resulted in a differential competing risk of earlier mortality, leading to survivor bias, and hence attenuation of associations among survivors at older ages.

In conclusion, our findings of increased odds of hospitalisation among ever smokers, net of the effect of comorbidity, underscore the additional burden of smoking on healthcare. The high rate of smoking behaviour in Lebanon, coupled with increasing costs of medical care and an ageing population, is likely to adversely impact on the healthcare bill in the country. Smoking-related health costs in Lebanon are estimated at around 146 million dollars. ${ }^{31}$ Furthermore, public resources and the governmental budget will bear the greatest burden as citizens continue to rely on services provided by the public insurance schemes. Lebanon ratified the WHO Framework Convention for Tobacco Control in December 2005, and passed the law in 2011 banning smoking in public places, restaurants, cafes and bars among others. While great strides have been achieved so far (eg, health warning labels on cigarette packages), smoking remains until today a socially accepted behaviour, with strategies for implementation of current policies being slow and not without obstacles. One major problem lies in the lack of dedicated funds for the enforcement of the tobacco control law, particularly for restriction of smoking behaviour in governmental public buildings and in restaurants and closed areas. Furthermore, the country lacks an effective national surveillance scheme of tobacco use and there is no proper planning of tobacco control initiatives. Our study calls for the need for serious efforts for closing the loopholes in the tobacco law and for proactive policies for an effective tobacco control policy in the country. This study is the first national survey to be conducted in Lebanon with results generalisable to the total population; it serves as a benchmark for future studies to assess whether the 2011 legislation has had an effect on the prevalence of smoking. Disease surveillance frameworks and continuous monitoring of NCD risk factors are increasingly warranted in Lebanon and other developing countries to provide stakeholders with timely information needed for development and assessment of policies and programmes. 
Acknowledgements The authors wish to thank Mr Mohamad Haidar for his contribution in the editing of an earlier version of the paper.

Contributors AMS contributed towards study design and logistics, data collection, conceptualisation, data analysis and interpretation, and significantly to the writing of the manuscript. MI contributed towards conceptualisation, data analysis and interpretation, as well as to the writing of the manuscript. $\mathrm{AD}$ and $\mathrm{MH}$ contributed to the data analysis and the writing of the manuscript. RN, SS and SF contributed to data interpretation and the writing of the manuscript. NH contributed towards study design, study logistics, data collection and interpretation, as well as to the writing of the manuscript. All authors critically reviewed the paper for intellectual content and approved the final draft.

Funding The study was funded by the Training Programs in Epidemiology and Public Health Interventions Network (TEPHINET-CDC), the WHOLebanon, and the Lebanese National Council for Scientific Research.

Competing interests None declared.

Ethics approval The study was approved by the Institutional Review Board of the American University of Beirut.

Provenance and peer review Not commissioned; externally peer reviewed.

Data sharing statement The study is based on secondary data analysis. The original data set is owned by the corresponding author and is made available to researchers and students within the Faculty of Health Sciences at the American University of Beirut. Researchers interested in using these data can contact the corresponding author with specific research questions and a proposal.

Open Access This is an Open Access article distributed in accordance with the Creative Commons Attribution Non Commercial (CC BY-NC 4.0) license, which permits others to distribute, remix, adapt, build upon this work noncommercially, and license their derivative works on different terms, provided the original work is properly cited and the use is non-commercial. See: http:// creativecommons.org/licenses/by-nc/4.0/

\section{REFERENCES}

1. World Health Organization. Tobacco [Fact sheet]; 2012. http://www. who.int/mediacentre/factsheets/fs339/en/

2. World Health Organization. The WHO report on the global tobacco epidemic. Geneva: 2008.

3. Hvidtfeldt UA, Rasmussen S, Grønbæk M, et al. Influence of smoking and alcohol consumption on admissions and duration of hospitalization. Eur J of Public Health 2010;20:376-82.

4. Sovinová $\mathrm{H}$, Csémy L, Procházka B, et al. Smoking attributable hospital treatment, treatment costs and smoking attributable mortality in the Czech Republic in 2002. Cent Eur J Public Health 2007:15:79-83.

5. Woodruff SI, Conway TL, Shillington AM, et al. Cigarette smoking and subsequent hospitalization in a cohort of young U.S. Navy female recruits. Nicotine Tob Res 2010;12:365-73.

6. Vander Weg MW, Rosenthal GE, Vaughan Sarrazin MV. Smoking bans linked to lower hospitalizations for heart attacks and lung disease among medicare beneficiaries. Health Aff (Millwood) 2012;31:2699-707.

7. Humair JP, Garin N, Gerstel E, et al. Acute respiratory and cardiovascular admissions after a public smoking ban in Geneva, Switzerland. PLOS ONE 2014;9:e90417.

8. Maciosek MV, Xu X, Butani AL, et al. Smoking-attributable medical expenditures by age, sex, and smoking status estimated using a relative risk approach. Prev Med 2015;77:162-7.
9. Sibai AM, Nasreddine L, Mokdad AH, et al. Nutrition transition and cardiovascular disease risk factors in the MENA Countries: Reviewing the evidence. Ann NutrMetab 2010;57:193-203.

10. Mokdad F, Mrad M, Ghorra R, et al. Tobacco consumption among physicians in Lebanon. Paper presented at the 3rd International Epidemiological Association in Eastern Mediterranean Regional Scientific Meeting; 1997.

11. Chaaya M, Awwad J, Campbell OM, et al. Demographic and psychosocial profile of smoking among pregnant women in Lebanon: public health implications. Matern Child Health J 2003;7:179-86.

12. Salameh P, Salamé J, Waked M, et al. Waterpipe dependence in university students and effect of normative beliefs: a cross-sectional. BMJ Open 2014;4:e004378.

13. Gaziano C. Kish Selection Method. In: Lavrakas PJ. Encyclopedia of survey research methods 2008:409-10, ISBN: 9781412918084.

14. Sibai AM, Costanian C, Tohme R, et al. Physical activity in adults with and without diabetes: from the 'high-risk' approach to the 'population-based' approach of prevention. BMC Public Health 2013;13:1002.

15. WHO STEPwise approach to Surveillance (STEPS): Chronic Diseases and Health Promotion. http://www.who.int/chp/steps/en/

16. The Lebanon STEPwise Survey Questionnaire, 2009 (in Arabic). http://www.csa.org.lb/cms/assets/questionnaire_nncd_rf_lebanon.pdf

17. Sjostram M, Ainsworth B, Bauman A, et al. Guidelines for data processing and analysis of the International Physical Activity Questionnaire (IPAQ)-short and long forms: Nov 2005. 2009. http:// www.ipaq.ki.se/scoring.pdf

18. Lu N, Han Y, Chen T, et al. Power analysis for cross-sectional and longitudinal study designs. Shanghai Arch Psych 2013;25:259-62.

19. Memon A, Moody PM, Sugathan TN, et al. Epidemiology of smoking among Kuwaiti adults: prevalence, characteristics, and attitudes. Bull World Health Organ 2000;78:1306-15.

20. Van Loon AJM, Tijhuis M, Surtees PG, et al. Determinants of smoking status: cross-sectional data on smoking initiation and cessation. Eur J Public Health 2005;15:256-61.

21. Bassiony MM. Smoking in Saudi Arabia. Saudi Med $J$ 2009;30:876-81.

22. Guindon GE, Boisclair D. Past, current and future trends in tobacco use. Health, Nutrition and Population (HNP) Discussion Paper. Economics of Tobacco Control paper, (6). Washington DC: World Bank, 2003. http://escholarship.org/uc/item/4q57d5vp

23. Hitchman SC, Fong GT. Gender empowerment and female-to-Male smoking prevalence ratios. Bull World Health Organ 2011;89:195-202.

24. Abou Daoud KT. Smoking habits of a Lebanese group and cancer of the lung and larynx. J Med Liban 1970;23:11-18.

25. Maziak W. Smoking in Syria: profile of a developing Arab country. In $J$ Tuberc Lung Dis 2002;6:183-91.

26. Morbidity and Mortality Weekly Representative (2003). Prevalence of selected risk factors for chronic disease-Jordan, 2002. http://www. cdc.gov $/ \mathrm{mmwr} / \mathrm{preview} / \mathrm{mmwrhtml} / \mathrm{mm} 5243 \mathrm{a} 3 . \mathrm{htm}$

27. Saxena A, Shan L, Reid C, et al. Impact of smoking status on early and late outcomes after isolated coronary artery bypass graft surgery. J Cardiol 2013;61:336-41.

28. Baumeister SE, Schumann A, Meyer C, et al. Effects of smoking cessation on health care use: is elevated risk of hospitalization among former smokers attributable to smoking-related morbidity? Drug Alcohol Depend 2007;88:197-203.

29. Gallus S, Muttarak R, Franchi M, et al. Why do smokers quit? Eur J Cancer Prev 2013;22:96-101.

30. Jerant A, Fiscella K, Franks P. Health characteristics associated with gaining and losing private and public health insurance: a national study. Med Care 2012;50:145-51.

31. Salti N, Chaaban J, Naamani N. The economics of tobacco in Lebanon: an estimation of the social costs of tobacco consumption. Subst Use Misuse 2014;49:735-42. 